\title{
Comparison of Outcomes between Fractional-Flow-Reserve- and Angiography-Directed Intervention in Non-ST Elevation Acute Coronary Syndrome
}

\author{
Yang Jianjun1, Pang Xiaohua1, Tu Xuemei1, Huang Gang² and Wang Hailong ${ }^{1}$
}

\begin{abstract}
Among the sick patients suffering from non-ST segment elevation acute coronary syndrome (NSTEACS), the accuracy of fractional flow reserve (FFR)-directed percutaneous coronary intervention $(\mathrm{PCl})$ or coronary artery bypass grafting (CABG) is still ambiguous. Studies were obtained from PubMed, Embase, Wanfang Data, and Cochrane Library electronic statistics from their initiation up to April 2018, to explore the differences between the FFR-directed approach and the coronary angiography (CA)/stress perfusion scintigraphy (SPS)-directed approach in the outcomes of NSTACS patients. Odds ratio was determined for individual studies, quality assessments, heterogeneity, and publishing bias analyses. In total, there were 5 studies involving 1,366 patients (606 FFR patients and 760 CA patients). Compared with CA, the collection of the studies indicated that FFR had a lower incidence of myocardial infarction (MI) (OR, 0.61; 95\% Cl: 0.39-0.96; $\mathrm{p}<0.05$ ). However, none showed important disparities in main adverse cardiovascular events (MACE, OR, 0.74; 95\% Cl: 0.53-1.03; $p=0.07)$, all-cause death rate $(\mathrm{OR}, 0.83 ; 95 \% \mathrm{Cl}: 0.45-1.54 ; p=0.56)$, and major bleeding (OR, 1.00; 95\%Cl: $0.25-4.03 ; p=1)$. The FFR-directed management of patients with NSTEACS had a close relationship with the serious decrease in incidence of MI without statistical significance. Future large-scale research, which is carried out at random and with a control, is needed to confirm these conclusions.
\end{abstract}

Key Words: Acute coronary syndrome (ACS), Fractional flow reserve (FFR), Meta, Myocardial infarction (MI).

\section{INTRODUCTION}

There is still controversy about the application of fractional flow reserve (FFR) to non-ST elevation acute coronary syndromes (ACS) because the benefits of FFR are not clear. In patients with non-ST segment elevation acute coronary syndrome (NSTEACS), the degree of coronary stenosis usually determines the choice of treatment options; and coronary angiography is used to assess the condition. ${ }^{1}$ However, the degree of coronary stenosis cannot be accurately evaluated with a subjective assessment of the lesion using coronary angiography to decide whether $\mathrm{PCl}$ or $\mathrm{CABG}$ would be the most effective choice. ${ }^{2,3}$ Subjective assessment of the lesion may be occurring in patients with ACS, involving unstable angina (UA), and non-ST segment elevation myocardial infarction (NSTEMI). We found that FFR is closely associated with cardiac ischemia and FFR showed an extremely positive correlation with the degree of coronary stenosis; therefore, FFR can be

1 Department of Cardiology, Heart Center, Chongqing Three Gorges Central Hospital, Wanzhou, Chongqing, 404000, China

2 Department of Cardiology, Suining Central Hospital, Suining, Sichuan, 629000, China

Correspondence: Dr. Wang Hailong, Department of Cardiology, Heart Center, Chongqing Three Gorges Central Hospital, 165\# Xincheng Road, Wanzhou, Chongqing, 404000, China E-mail: wangjinlong2007666@163.com

Received: July 05, 2018; Accepted: September 26, 2018

All authors contributed equally to this work applied to assess the capability of affected coronary blood flow.2,4-6 The meta-reasoning was carried out in order to find the discrepancies between FFR-directed and CA/SPSR-directed approaches in the outcomes of patients with NSTACS.

\section{METHODOLOGY}

The meta-reasoning was carried out by applying the Preferred Reporting Items for Systematic Reviews and Meta-reasoning (PRISMA) statement under the guidance. ${ }^{7}$ Two investigators (J.J.Y. and X.H.P.) methodically retrieved studies from databases-PubMed, Embase, Wanfang Data, and the Cochrane Central Registry of Controlled Trials from their inception up to April 2018 with no language limitations. Medical subject heading terms and important words applied included: "unstable angina or UA," "non-ST elevated myocardial infarction or NSTEMI," "acute coronary syndrome or ACS," and "Fractional flow reserve or FFR."

The authors examined controlled experiments of NSTACS patients (including NSTEMI, and UA cases) in which FFR-directed revascularisation was applied in contrast to CA-SPS-directed revascularisation. Standard inclusion research options included control tests carried out in people who suffer from ACS with ongoing ischemic signs and the sick patients who were anticipated to have $\mathrm{CA}$, with coronary artery stenosis accounting for more than $30 \%$, and with an interference of FFR in contrast to CA-SPS-directed revascularisation. We removed the studies that referred to the sick patients 
showing steady coronary artery disease (CAD) and NonST elevated myocardial infarction (NSTEMI) studies that were carried out without control, and studies that had no record of the long-term outcomes. In view of the study results, we had no restrictions on eligibility.

Two researchers (Pang X.H, and Yang J.J) independently extracted the following data from each study: the name of the primary writer, the arrangement of the research, research place, the case scale, the basic features of the research, the ratio of $\mathrm{PCl}$ sick patients, and the period of the after-trials. All divergences were resolved by discussion with a third investigator (Wang H.L). Results of the assessment consist of death and all-cause death rate, MI, main adverse cardiovascular events (MACE; cardiac death or unexpected hospitalisation for MI or

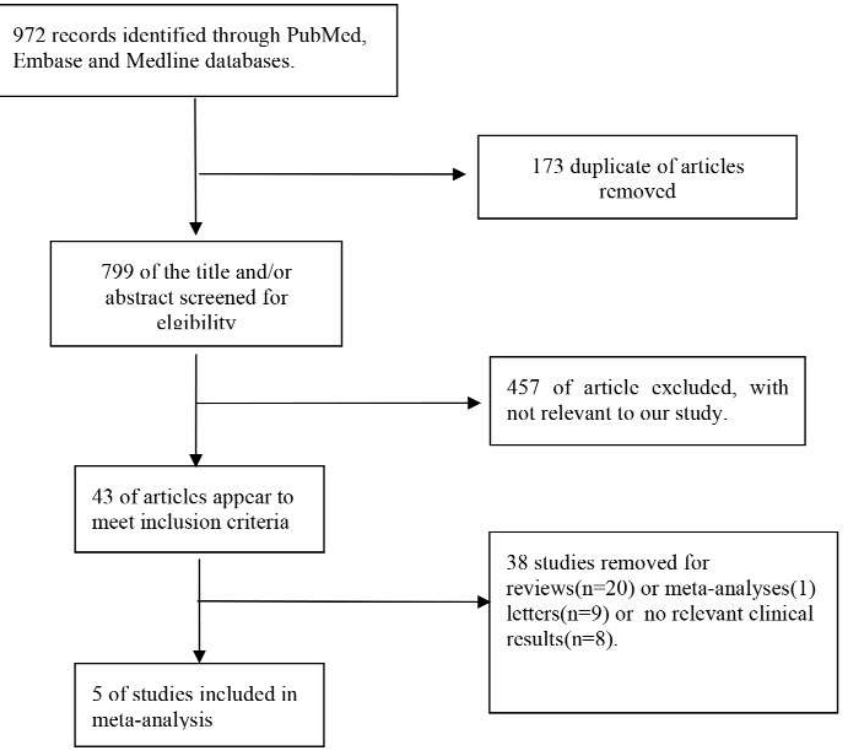

Figure 1: Search strategy conducted for all the included trials. $\mathrm{MeSH}=$ Medical subject headings. heart failure), and index hospitalisation extended. Major bleeding was reported in these two studies.6,8

The single adventure of bias in each study was assessed by applying the Cochrane adventure of bias estimation device. ${ }^{9}$ Data reasoning was based upon the PRISMA statement and the Cochrane Collaboration. Review Manager (RevMan) 5.1 was used to perform the meta-analyses. Heterogeneity between the studies was assessed using 12 statistics of inconsistency and Chisquare test of heterogeneity. $I^{2}$ values of $75 \%, 50 \%$, and $25 \%$ indicated as, respectively, high, medium, and low heterogeneity. 10 The Mantel-Haenszel method was applied to compute the summary estimate of odd risks (ORs) with their 95\% confidence intervals (Cls). Reported values are two-tailed, and the results of hypothesis testing were deemed statistically different at $p<0.05$. Funnel plots, Egger's test, and Begg's log-rank testing were applied to test small sample studies, including publication bias.

\section{RESULTS}

In total, 969 articles were acquired from the Embase, PubMed, Cochrane, and Wanfang Data databases. After abortive verification, 396 copies were excluded. Of the remaining 573 articles, 530 articles were excluded because they did not pertain to the topic. The remaining 43 full-text articles were assessed as qualified, with 38 articles excluded in that they belonged to metaanalyses, review, or letters to proofreaders; no relevant clinical results were recorded on the clinical endpoints (Figure 1).6,8,11-13

In total, there were five reflective researches included, with a total of 1366 ACS patients (consisting of 606 cases in the FFR group and 760 cases in the CA group) identified in this meta-analysis. The median age of the patients in the study was 62.1 years; the median

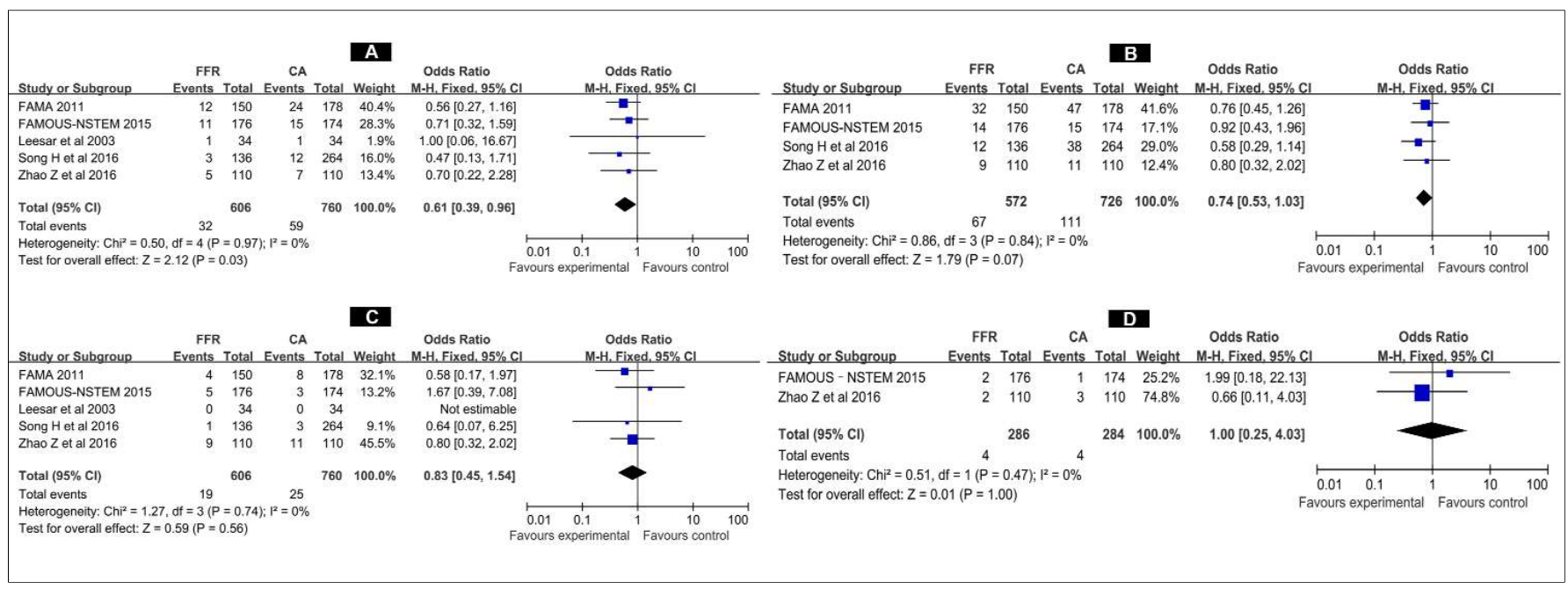

Figure 2: (A) Fixed-effect meta-analysis for myocardial infarction. The figure presents the number of events, the number of patients in the treatment and control groups, the odds ratio (OR) and $95 \%$ confidence interval $(\mathrm{Cl})$ for each trial, the overall OR estimate with $95 \% \mathrm{Cl}$ and the p-value for the association test, the $p$-value for the heterogeneity test, and between-trial inconsistency (I2) measures. (B) Fixed-effect meta-analysis for MACE. (C) Fixed-effect meta-analysis for all-cause mortality. (D) Fixed-effect meta-analysis for major bleeding. 
age of the CA-directed revascularization group was 61.0 years and the moderate age of the FFR-directed revascularization group was 63.5 years. The characteristics of the baseline in the studies are presented in
Table I, and features of the patients in every trial are presented in Table II. All five articles included in the current meta-analysis were from different study groups and different countries. The diagnostic criteria for

Table I: Baseline characteristics of randomised studies.

\begin{tabular}{|c|c|c|c|c|c|c|}
\hline \multirow{2}{*}{$\begin{array}{l}\text { Randomised } \\
\text { studies (year) }\end{array}$} & \multicolumn{2}{|c|}{ Sample size } & \multirow[t]{2}{*}{ Inclusion criteria } & \multirow[t]{2}{*}{ Exclusion criteria } & \multirow[t]{2}{*}{ Endpoints } & \multirow{2}{*}{$\begin{array}{l}\text { Mean } \\
\text { follow-up } \\
\text { period } \\
\text { (months) }\end{array}$} \\
\hline & $\begin{array}{l}\text { Intervention } \\
\text { (FFR- } \\
\text { directed } \\
\text { approach) }\end{array}$ & $\begin{array}{l}\text { Control } \\
\text { (CA- or SPS- } \\
\text { directed } \\
\text { approach) }\end{array}$ & & & & \\
\hline $\begin{array}{l}\text { Zhao Z; Ke L } \\
\text { (2016) }\end{array}$ & 110 & 110 & $\begin{array}{l}\text { Patients with NSTEMI who are } \\
\text { older than } 65 \text { years of age with } \\
\text { acute ischemic symptoms and } \\
\text { abnormal myocardial markers, but } \\
\text { without ST-segment elevation on } \\
\text { the electrocardiogram. }\end{array}$ & $\begin{array}{l}\text { Ongoing ischemic } \\
\text { symptoms after medical } \\
\text { therapy; cardiogenic } \\
\text { shock or hemodynamic } \\
\text { instability; intolerance to } \\
\text { antiplatelet drugs; } \\
\text { ineligible for PCl; } \\
\text { CAD<30\% severity; } \\
\text { highly tortuous or } \\
\text { calcified coronary } \\
\text { arteries; noncoronary } \\
\text { cardiosurgery; and life } \\
\text { expectancy <1 year. }\end{array}$ & $\begin{array}{l}\text { Adverse events, including major } \\
\text { adverse cardiovascular events defined } \\
\text { as cardiovascular death, non-fatal } \\
\text { myocardial infarction, or unplanned } \\
\text { hospitalisation for heart failure, } \\
\text { major adverse cardiovascular and } \\
\text { cerebrovascular events defined as } \\
\text { cardiovascular death, non-fatal } \\
\text { myocardial infarction, unplanned } \\
\text { hospitalisation for stroke, or transient } \\
\text { ischemic attack, all-cause mortality, } \\
\text { contrast nephropathy, and major } \\
\text { bleeding, and therapeutic strategies } \\
\text { (PCl or medical therapy alone). }\end{array}$ & 12 \\
\hline $\begin{array}{l}\text { FAMOUS- } \\
\text { NSTEMI } \\
(2015)\end{array}$ & 176 & 174 & $\begin{array}{l}\text { Patients with a clinical diagnosis of } \\
\text { recent NSTEMI and with at least } \\
\text { one risk factor for coronary artery } \\
\text { disease, with planned invasive } \\
\text { management within } 72 \text { h of the } \\
\text { index episode of event or history of } \\
\text { recurrent ischemic symptoms within } \\
5 \text { days of NSTEMI. At least one } \\
\text { coronary stenosis } \geq 30 \% \text { severity } \\
\text { with normal coronary blood flow. } \\
\text { Thrombolysis in myocardial } \\
\text { infarction (TIMI) grade III in which } \\
\text { FFR measurement might have a } \\
\text { diagnostic value. }\end{array}$ & $\begin{array}{l}\text { Presence of ischemic } \\
\text { symptoms that were not } \\
\text { controlled by medical } \\
\text { therapy, hemodynamic } \\
\text { instability, MI with } \\
\text { persistent ST elevation, } \\
\text { intolerance to anti- } \\
\text { platelet drugs, ineligible } \\
\text { for coronary } \\
\text { revascularisation, a } \\
\text { treatment plan for non- } \\
\text { coronary heart surgery } \\
\text { (e.g., valve surgery), a } \\
\text { history of prior CABG, } \\
\text { angiographic evidence of } \\
\text { severe (e.g., diffuse } \\
\text { calcification) or mild } \\
\text { (30\% severity) coronary } \\
\text { disease, and a life } \\
\text { expectancy of } 1 \text { year. }\end{array}$ & $\begin{array}{l}\text { Between-group difference in the } \\
\text { proportion of patients allocated to } \\
\text { medical management. The feasibility } \\
\text { and safety of routine FFR } \\
\text { measurement. The relationship } \\
\text { between FFR and coronary stenosis } \\
\text { severity by visual assessment of the } \\
\text { angiogram. MACE defined as } \\
\text { cardiac death or hospitalisation for } \\
\text { myocardial infarction or heart failure } \\
\text { after randomisation. Cardiovascular } \\
\text { death, stroke, transient ischemic } \\
\text { attack, contrast nephropathy, and } \\
\text { bleeding were also prospectively } \\
\text { recorded. Index hospitalisation } \\
\text { resource used including: material, } \\
\text { procedure, hospitalisation, and in- } \\
\text { hospital event costs. Health-related } \\
\text { quality of life. }\end{array}$ & 12 \\
\hline FAME (2011) & 150 & 178 & $\begin{array}{l}\text { Patients with multivessel CAD } \\
\text { undergoing PCI by stenting with } \\
\text { drug-eluting stents, UA (with or } \\
\text { without transient ST-segment } \\
\text { changes) and NSTEMI with positive } \\
\text { troponin but total creatine kinase of } \\
<1000 \mathrm{U} / \mathrm{l} \text {. }\end{array}$ & $\begin{array}{l}\text { Left main disease, } \\
\text { previous CABG, and } \\
\text { STEMI } 5 \text { days before. }\end{array}$ & $\begin{array}{l}\text { MACE defined as composite of } \\
\text { death from any cause, MI, any } \\
\text { repeat revascularisation, and their } \\
\text { individual components. }\end{array}$ & 24 \\
\hline $\begin{array}{l}\text { Leesar et al. } \\
(2003)\end{array}$ & 35 & 35 & $\begin{array}{l}\text { An episode of angina lasting }>20 \\
\text { min or recurrent episodes of angina } \\
\text { while at rest and had at least one of } \\
\text { the following: a new finding of ST- } \\
\text { segment depression; transient }(<20 \\
\text { min) ST-segment elevation; a new } \\
\text { finding of T-wave inversion in at } \\
\text { least two leads; elevated levels of } \\
\text { cardiac markers; a history of MI, } \\
\text { including a Q-wave on the } \\
\text { electrocardiogram or previous } \\
\text { admission with a diagnosis of MI; } \\
\text { and evidence of prior CAD or } \\
\text { history of PCl. }\end{array}$ & $\begin{array}{l}\text { Incessant chest pain that } \\
\text { does not respond to } \\
\text { medical therapy; left } \\
\text { main or multivessel } \\
\text { CAD; prior CABG; } \\
\text { vessels that were totally } \\
\text { occluded or supplying an } \\
\text { akinetic territory by } \\
\text { visual assessment of the } \\
\text { left ventricular } \\
\text { angiogram. }\end{array}$ & $\begin{array}{l}\text { Death, } \mathrm{MI}, \mathrm{CABG}, \mathrm{PCI} \text {, and } \\
\text { readmission because of UA. }\end{array}$ & 13 \\
\hline $\begin{array}{l}\text { Song H; Li H } \\
(2016)\end{array}$ & 136 & 264 & $\begin{array}{l}\text { Non-ST elevation acute coronary } \\
\text { syndromes (NSTEACS), NSTEACS } \\
\text { patients who had moderate } \\
\text { coronary lesions; Double } \\
\text { antiplatelet therapy for at least } 1 \\
\text { year. }\end{array}$ & $\begin{array}{l}\text { Patients with } \\
\text { hemodynamically } \\
\text { unstable or hyperacute } \\
\text { period of acute } \\
\text { myocardial infarction. }\end{array}$ & $\begin{array}{l}\text { Major adverse cardiac events } \\
\text { (MACE), death, non-fatal myocardial } \\
\text { infarction (MI), target vessel } \\
\text { revascularisation (TVR), and } \\
\text { procedure costs. }\end{array}$ & 10 \\
\hline
\end{tabular}


Table II: Patient characteristics in each randomised trial.

\begin{tabular}{|c|c|c|c|c|c|c|c|c|c|c|}
\hline \multirow[t]{2}{*}{ Demographics } & \multicolumn{2}{|c|}{ Zhao Z; Ke L } & \multicolumn{2}{|c|}{ FAMOUS-NSTEMI } & \multicolumn{2}{|c|}{ FAME } & \multicolumn{2}{|c|}{ Leesar et al. } & \multicolumn{2}{|c|}{ Song $\mathrm{H}$; Li H } \\
\hline & $\begin{array}{c}\text { FFR-directed } \\
(110)\end{array}$ & $\begin{array}{c}\text { CA-directed } \\
(110)\end{array}$ & $\begin{array}{c}\text { FFR-directed } \\
(176)\end{array}$ & $\begin{array}{c}\text { CA-directed } \\
(174)\end{array}$ & $\begin{array}{c}\text { FFR-directed } \\
(150)\end{array}$ & $\begin{array}{c}\text { CA-directed } \\
(178)\end{array}$ & $\begin{array}{c}\text { FFR-directed } \\
\text { (35) }\end{array}$ & $\begin{array}{c}\text { CA-directed } \\
\text { (35) }\end{array}$ & $\begin{array}{c}\text { FFR-directed } \\
(142)\end{array}$ & $\begin{array}{c}\text { CA-directed } \\
(284)\end{array}$ \\
\hline Age, mean & $70 \pm 3.7$ & $70 \pm 3.4$ & $62.3 \pm 11$ & $61.6 \pm 11.1$ & $65.6 \pm 10$ & $64.2 \pm 10.5$ & $59 \pm 6$ & $55 \pm 4$ & $58.75 \pm 9.86$ & $55.76 \pm 9.63$ \\
\hline Sex, male $(n)$ & 75 & 78 & 133 & 127 & 110 & 116 & 24 & 22 & 105 & 225 \\
\hline Smoking history $(\mathrm{n})$ & 70 & 69 & 127 & 118 & 43 & 55 & 20 & 15 & 69 & 150 \\
\hline Prior CAD $(n)$ & 24 & 23 & 22 & 22 & 66 & 78 & 9 & 14 & - & - \\
\hline Hypertension (n) & 81 & 83 & 78 & 81 & 90 & 122 & 25 & 26 & 89 & 197 \\
\hline Diabetes mellitus $(n)$ & 40 & 36 & 26 & 26 & 33 & 38 & 13 & 11 & 39 & 72 \\
\hline Hyperlipidemia (n) & 90 & 93 & 71 & 56 & 101 & 129 & 19 & 22 & 25 & 51 \\
\hline $\mathrm{PCl} / \mathrm{CABG}$ & 95 & 104 & 136 & 151 & 20 & 25 & 2 & 1 & 52 & 133 \\
\hline $\mathrm{MI}(\mathrm{n})$ & 5 & 7 & 11 & 15 & 12 & 24 & 1 & 1 & 3 & 12 \\
\hline MACE $(n)$ & 9 & 11 & 14 & 15 & 32 & 47 & NA & NA & 12 & 38 \\
\hline Death $(n)$ & 9 & 11 & 5 & 3 & 4 & 8 & 0 & 0 & 1 & 3 \\
\hline Major bleeding $(n)$ & 2 & 3 & 2 & 1 & NA & NA & NA & NA & NA & NA \\
\hline
\end{tabular}

NA $=$ Not available

Table III: Quality evaluation of the included studies.

\begin{tabular}{|c|c|c|c|c|c|c|}
\hline Studies & $\begin{array}{l}\text { Sample-size } \\
\text { calculation }\end{array}$ & $\begin{array}{l}\text { Inclusion and } \\
\text { exclusion criteria }\end{array}$ & Randomisation & $\begin{array}{l}\text { Allocation } \\
\text { concealment }\end{array}$ & $\begin{array}{c}\text { Blinded assessment } \\
\text { of outcomes }\end{array}$ & $\begin{array}{l}\text { Reporting potential } \\
\text { conflicts of interest } \\
\text { and study funding }\end{array}$ \\
\hline Leesar et al. (2003) & No & Yes & Yes & No & No & No \\
\hline FAMA (2011) & No & Yes & Yes & No & No & Yes \\
\hline FAMOUS-NSTEM (2015) & Yes & Yes & Yes & Yes & Yes & Yes \\
\hline Song $\mathrm{H}$ et al. (2016) & No & Yes & No & No & No & Yes \\
\hline Zhao Z et al. (2016) & No & Yes & Yes & No & No & No \\
\hline
\end{tabular}

coronary artery disease, as well as the cut-off thresholds for FFR and CA, might be different.

Table III lists the quality estimation for each included study. As we can see in this chart, five studies in this meta-analysis reported inclusion and exclusion criteria, four reported randomisation, two reported that there was no potential conflict of interest and listed their sources of financial support; one of the studies described the calculation of sample size, allocation of hidden elements, and blind evaluation of the results in detail. Because five published studies met the inclusion criteria and the information in these studies was less comprehensive than in other studies, the overall quality of these works in the meta-analysis was moderate.

The frequency of $\mathrm{Ml}$ during the after-trial process was $5.3 \%$ for the group of the sick patients who received FFR-directed treatment versus $7.8 \%$ for the CA/SPS-directed treatment. Compared with CA-directed revascularization, FFR-directed revascularisation had a close relationship with a significant decrease of frequency of MI (OR: $0.61,95 \% \mathrm{Cl}$ : 0.39-0.96; p <0.05; I2=0\%). Due to low heterogeneity, the fixed-effect model was used to calculate the statistics. Egger's and Begg's tests were used to estimate publication bias (Figure 2A).

The frequency of MACE was $11.7 \%$ in sick patients with FFR-directed treatment versus $15.2 \%$ in the CA/SPSdirected treatment. There were no significant differences in the case of MACE (OR: $0.74,95 \% \mathrm{Cl}: 0.53-1.03$; $p=0.07 ; \mathrm{I} 2=0 \%$ ) between two groups (Figure $2 \mathrm{~B}$ ).
The frequency of all-cause death rate was $3.1 \%$ in sick patients who received FFR-directed treatment versus $3.3 \%$ in patients who received CA/SPS-directed treatment. No important discrepancy existed between these two groups in the frequency of all-cause death rate (OR: $0.83,95 \% \mathrm{Cl}: 0.45-1.54 ; \mathrm{p}=0.56 ; \mathrm{I} 2=0 \%)$ without important heterogeneity in the tests (Figure 2C).

The frequency of major bleeding was $1.3 \%$ in sick patients who received FFR-directed treatment competing against $1.4 \%$ in the sick patients who received CA/SPS-directed treatment. No important discrepancy existed between these groups in the incidence of major bleeding (OR: $1.00,95 \% \mathrm{Cl}: 0.25-4.03 ; p=1.00 ; 12=0 \%$ ) with no significant heterogeneity in the trials (Figure 2D).

Begg's funnel plot was used to determine whether our conclusions were affected by any publication bias. The results showed no obvious asymmetry for fractional flow reserve-directed management of acute coronary syndromes, indicating that the conclusion of this metaanalysis was not influenced by publication bias.

\section{DISCUSSION}

Egger's tests were of no importance for the outcomes of the studies, and the funnel plot displayed symmetry that is in line with publication bias. The meta-reasoning disclosed that the FFR-directed treatment of NSTEACS patients was related to an important decrease of incidence of $\mathrm{Ml}$ during the process of after-trials and that the FFR-directed treatment of NSTEACS patients no 
correlated with decrease in the incidence of MACE. Although the heterogeneity was low, the FFR-directed management of NSTEACS patients had a significant trend in reducing Ml. There were no statistical significances in the incidence of MACE, all-cause death rate and major bleeding between the FFR-directed treatment group and the CA/SPS-directed treatment group, but our meta-analysis showed that the FFRdirected treatment of ACS patients was still not related to modest reduction in incidence of MACE during the follow-up period.

In a wide range of studies, FFR had been used to determine the practical importance of moderate coronary artery stenosis.14,15 For NSTEACS sick patients, who have moderate coronary stenosis, FFRdirected therapy was found to further decrease the incidence of myocardial infarction than the assessment of coronary angiographic. ${ }^{16,17}$ In NSTEACS patients with moderate coronary stenosis, the revascularisation programme is based upon the severity of the anatomical assessment of the coronary artery, rather than a functional assessment. Based on the earlier metareasoning by Briasoulis and his coworkers, their studies displayed no important difference between the FFRdirected management of NSTEACS patients and the CA-directed management of NSTEACS patients in reducing the incidence of MI. Our study found that there is an important discrepancy between the two groups in reducing the incidence of MI. FFR-directed revascularisation can greatly reduce the frequency of $\mathrm{MI}$ in sick patients with NSTEACS, and this trend was more obvious after increasing the data from the studies. ${ }^{18}$ In addition, large trials may be able to prove these outcomes in the future, then the decrease of MACE related to FFR-directed revascularisation will probably be more obvious. FFR helped to more accurately guide the need for PCl or CABG in the NSTEACS patients. During the acute stage of acute coronary syndromes, the seriousness of the coronary artery stenoses can be estimated accurately by FFR. This provides a decision about the demand for additional revascularisation to be made that might be beneficial to better risk stratification. In these studies, the presence of CAD was defined by the visual assessment of the stenosis. However, the accurate judgment of the hemodynamic seriousness of the coronary artery stenoses with fractional flow reserve (FFR) during the acute stage of an NSTEACS can enhance the risk stratification and make the continuation of the hospital stay short by reducing the demand for additional non-invasive stress tests so as to disclose residual myocardial ischemia. ${ }^{19}$ FFR-directed revascularisation was conducive to achieve the best medical treatment and decrease healthcare costs.

A prior meta-analysis by Briasoulis and colleagues failed to show that there was a substantial statistical significance between the FFR and CA groups in MI,
MACE, all-cause mortality, ${ }^{15}$ and major bleeding because only one study was included about major bleeding in their meta-analysis. There were no significant differences in FFR-directed revascularisation compared to CA-directed revascularisation in the incidence of major bleeding and all-cause mortality. However, the meta-analysis showed a significance difference between the FFR-directed management of NSTEACS patients and the CA-directed management of NSTEACS patients in reducing the incidence of MI.

There are several limitations to consider, when explaining the research outcomes. First, because of being devoid of professional RCTs paying attention to this topic, statistics were only obtained from observational studies, surely leading to inherent bias, equal design bias, selection bias, treatment bias, and publication bias. Second, instead of using an individual ill-patient-level statistic, concluded published event rate was applied for every study, then confounding factors and selection bias could not be wiped out in these studies and some clinical findings are under the control of between-study heterogeneity. Finally, the specific method of CABG or PCl could not be reasoned out. Nevertheless, in spite of the limitations, this data cater to crucial demand for an all-round comparison between the two guided methods, which could improve informed decision-making for the sick patients and physicians to choose an ideal method for revascularisation in sick patients with NSTEACS.

\section{CONCLUSION}

FFR-directed management of NSTEACS patients could significantly reduce the incidence of $\mathrm{MI}$, which would improve the quality of life of patients, reduce the rehospitalisation rate, and lower medical expenses. There was no statistical significance in the incidence of death, or all-cause mortality, MACE, and major bleeding due to limited data from randomised studies. If future large-scale researches will prove these outcomes, then the decrease in MACE related to FFR-directed revascularisation will probably be more obvious.

\section{REFERENCES}

1. Hamm CW, Bassand JP, Agewall S. ESC guidelines for the management of acute coronary syndromes in patients presenting without persistent ST-segment elevation: The task force for the management of acute coronary syndromes (ACS) in patients presenting without persistent ST-segment elevation of the European Society of Cardiology (ESC), Eur Heart $J$ 2011; 32:2999-3054.

2. White $\mathrm{CW}$, Wright $\mathrm{CB}$, Doty DB, Hiratza LF. Does visual interpretation of the coronary arteriogram predict the physiologic importance of a coronary stenosis? N Engl J Med 1984; 310:819-24.

3. Terkelsen CJ, Lassen JF, Nørgaard BL. Mortality rates in patients with ST-elevation vs. non-ST elevation acute myocardial infarction: observations from an unselected cohort, Eur Heart J 2005; 26:18-26. 
4. Topol EJ, Nissen SE. Our preoccupation with coronary luminology. The dissociation between clinical and angiographic findings in ischemic heart disease. Circulation 1995; 92:2333-42.

5. Marcus ML, Skorton DJ, Johnson MR. Visual estimates of percent diameter coronary stenosis: A battered gold standard. J Am Coll Cardiol 1988; 11:882-5.

6. Layland J, Oldroyd KG, Curzen N. Fractional flow reserve vs. angiography in guiding management to optimize outcomes in non-ST-segment elevation myocardial infarction: the British Heart Foundation FAMOUS-NSTEMI randomized trial. Eur Heart J 2015; 36:100-11.

7. Liberati A, Altman DG, Tetzlaff J. The PRISMA statement for reporting systematic reviews and meta-analyses of studies that evaluate health care interventions: explanation and elaboration. J Clin Epidemiol 2009; 62:e1-34.

8. Zhang Z, Li K, Tian J. Efficacy and safety outcomes of fractional flow reserve in guiding clinical therapy of non-STsegment elevation myocardial infarction compared with angiography alone in elderly Chinese patients. Clin Interv Aging 2016; 11:1751-4.

9. Higgins JP. The Cochrane Collaboration's tool for assessing risk of bias in randomised trials. BMJ 2011; 343:d5928.

10. Higgins JP, Thompson SG, Deeks JJ, Altman DJ. Measuring inconsistency in meta-analyses. BMJ 2003; 327:557-60.

11. Leesar MA, Abdul-Baki T, Akkus NI. Use of fractional flow reserve versus stress perfusion scintigraphy after unstable angina. Effect on duration of hospitalization, cost, procedural characteristics, and clinical outcome. J Am Coll Cardiol 2003; 41:1115-21.
12. Sels JW. Fractional flow reserve in unstable angina and nonST-segment elevation myocardial infarction experience from the FAME (Fractional flow reserve versus Angiography for Multivessel Evaluation) study. JACC Cardiovasc Interv 2011; 4:1183-9.

13. Song HF, LI H, LI X. Outcome of patients with acute coronary syndromes treated with FFR-guided versus CAG-guided strategy. Chin J Inpervenp Cardiol 2016; 4:186-90.

14. de Bruyne B. Simultaneous coronary pressure and flow velocity measurements in humans. Feasibility, reproducibility, and hemodynamic dependence of coronary flow velocity reserve, hyperemic flow versus pressure slope index, and fractional flow reserve. Circulation 1996; 94:1842-9.

15. Pijls NH. Fractional flow reserve. A useful index to evaluate the influence of an epicardial coronary stenosis on myocardial blood flow. Circulation 1995; 92:3183-93.

16. Tonino PA. Fractional flow reserve versus angiography for guiding percutaneous coronary intervention. $N$ Engl $\mathrm{J}$ Med 2009; 360:213-24.

17. de Bruyne B. Fractional flow reserve-guided $\mathrm{PCl}$ versus medical therapy in stable coronary disease. N Engl J Med 2012; 367: 991-1001.

18. Briasoulis A, Palla M, Mostafa A. Fractional flow-guided management in patients with acute coronary syndromes: A systematic review and meta-analysis. Int J Cardiol 2015; 187: 334-7.

19. Carrick D, Behan M, Foo F. Usefulness of fractional flow reserve to improve diagnostic efficiency in patients with non-ST elevation myocardial infarction. Am J Cardiol 2013; 111:45-50.

....占.... 